\title{
artigo
}

Ribeiro, L.S.; Modesto, C.M.S.; Martinho, N.J.; Mendonça, M.G.S.; Marta, C.B.; Barthus, D.M.S.; Nunes, J.R.S.;

Cultura e saúde: desvelando o autocuidado entre mulheres quilombolas

\section{Cultura e saúde: desvelando o autocuidado entre mulheres quillombolas}

\author{
Culture and health: unveiling self-care among quilombolas women \\ Cultura y salud: desarrollar el cuidado personal entre las mujeres quilombolas
}

\begin{abstract}
RESUMO
Este estudo descritivo com abordagem qualitativa tem como objetivo desvelar a compreensão e as práticas das mulheres quilombolas quanto ao autocuidado em saúde e, intercambiar saberes e fazeres culturais populares com os acadêmicos. Os dados foram coletados com mulheres negras da comunidade quilombola Mutuca-MT, através de rodas de conversas permeadas com dinâmicas estimuladoras para participação. Foi evidenciado que as mulheres quilombolas desenvolvem ações de autocuidado com base nas tradições culturais aprendidas com seus antepassados e muitas receiam voltar aos serviços de saúde por se sentirem desrespeitadas pelos profissionais quanto aos seus saberes e fazeres culturais. Consideramos que se faz necessário os cursos da área da saúde abordarem no processo de formação dos futuros profissionais conhecimentos que os habilitem a desenvolverem uma abordagem e negociação cultural com os povos das comunidades tradicionais na arte de cuidar da saúde em suas diversas dimensões. DESCRITORES: Autocuidado; Quilombo; Mulheres Negras.
\end{abstract}

\section{ABSTRACT}

This descriptive study with a qualitative approach aims to reveal the understanding and practices of quilombola women regarding self-care in health and to exchange knowledge and popular cultural practices with academics. Data were collected with black women from the Mutuca-MT quilombola community, through conversation circles permeated with stimulating dynamics for participation. It was evident that quilombola women develop self-care actions based on cultural traditions learned from their ancestors and many are afraid to return to health services because they feel disrespected by professionals regarding their knowledge and cultural practices. We believe that it is necessary for courses in the area of health to address, in the process of training future professionals, knowledge that will enable them to develop an approach and cultural negotiation with the people of traditional communities in the art of health care in its various dimensions.

DESCRIPTORS: Self-care; Quilombo; Black Women.

\section{RESUMEN}

Este estudio descriptivo con enfoque cualitativo tiene como objetivo revelar el entendimiento y las prácticas de las mujeres quilombolas en relación con el autocuidado en salud e intercambiar conocimientos y prácticas culturales populares con académicos. Los datos se recolectaron con mujeres negras de la comunidad quilombola Mutuca-MT, a través de círculos de conversación impregnados de dinámicas estimulantes para la participación. Se evidenció que las mujeres quilombolas desarrollan acciones de autocuidado basadas en tradiciones culturales aprendidas de sus antepasados y muchas tienen miedo de regresar a los servicios de salud porque se sienten irrespetadas por los profesionales con respecto a sus conocimientos y prácticas culturales. Creemos que es necesario que los cursos en el área de la salud aborden, en el proceso de formación de los futuros profesionales, conocimientos que les permitan desarrollar un acercamiento y negociación cultural con las personas de las comunidades tradicionales en el arte de la salud en sus diversas dimensiones.

DESCRIPTORES: Autocuidado; Quilombo; Mujeres Negras.

RECEBIDO EM: 15/03/2020 APROVADO EM: 15/03/2020

\section{Luciene Souza Ribeiro}

Bacharel em Enfermagem pela Universidade Federal de Mato Grosso - UFMT (2019).

ORCID: 0000-0003-0480-1713

\section{Closeny Maria Soares Modesto}

Enfermeira. Graduação pela Universidade Estadual de Mato Grosso - UEMT (1998).

ORCID: 0000-0001-8883-6459 


\section{Neudson Johnson Martinho}

Mestre em Enfermagem em Saúde Comunitária e Doutor em Educação. Graduado em Enfermagem pela Universidade de Fortaleza - UNIFOR (1997).

ORCID: 0000-0001-9176-2729

\section{Marilda Gomes da Silva Mendonça}

Bacharel em Enfermagem pela Universidade Federal de Mato Grosso - UFMT (2019).

ORCID: 0000-0001-5838-4084

\section{Cristiano Bertolossi Marta}

Graduação em Enfermagem pela Universidade do Estado do Rio de Janeiro (2002).

ORCID: 0000-0002-0635-7970

\section{Dhannyella Moura da Silva Barthus}

Bacharel em Enfermagem. Graduação em Enfermagem pela Universidade Federal de Mato Grosso (2019). ORCID: 0000-0002-2190-9550

\section{Josué Ribeiro da Silva Nunes \\ Biólogo. Graduado em Ciências Biológicas \\ ORCID: 0000-0003-3927-5063}

\section{INTRODUÇÃO}

A s mulheres são as principais usuárias dos serviços de saúde. Os motivos para que elas utilizem tais serviços são os mais variados apontados pelas características inerentes à natureza feminina, como: maternidade, sentimento de cuidado, compaixão, necessidade quanto ao seu próprio cuidado e acompanhamento aos seus entes queridos, vizinhos e/ou amigos ${ }^{(1)}$.

Populações mais carentes e algumas socialmente excluídas, tais como mulheres negras, quilombolas, população LGBT e residentes em áreas de difícil acesso geográfico encontram dificuldades para usufruir esses serviços. Tal fenômeno se caracteriza como um nó crítico no Sistema Único de Saúde (SUS), afetando principalmente moradores de comunidades remanescentes quilombolas ${ }^{(2)}$.

O Ministério da Saúde define comunidades remanescentes quilombolas (CRQ) como espaços nos quais vivem os grupos étnicos raciais com presunção de ancestralidade afrodescendente, como os descendentes de mulheres e homens escravizados, ex-escravizados e negros livres. Entretanto, essas comunidades vivenciam desigualdades sociais e de saúde por residirem em isolamento físico e social( ${ }^{(3)}$.

Os autores ${ }^{(2,4)}$ ressaltam que, na maioria das vezes, mulheres negras encontram-se abaixo da linha da pobreza, com dificuldades de inserção no mercado de trabalho e em situação de analfabetismo, o que as torna vulneráveis à tripla discriminação social. Sendo assim, frente ao processo de exclusão e discriminação, tais mulheres podem desenvolver sofrimento psíquico e, consequentemente, possuírem inacessibilidade a uma assistência à saúde mais justa e de qualidade.

Frente a tal problemática, quanto à dificuldade de acesso aos serviços de saúde vivenciados pelas mulheres negras, de modo específico quando se trata da mulher negra quilombola, o Grupo de Pesquisas Multiprofissionais em Educação e Tecnologias em Saúde (PEMEDUTS) da Universidade Federal de Mato Grosso (UFMT) sentiu a necessidade de elaborar e desenvolver o projeto de pesquisa, com interface na extensão, denominado "Práticas culturais em saúde: o cuidado e a educação popular em saúde na luta pela vida em uma comunidade quilombola do Estado de Mato Grosso", visando compreender as diversas nuances que permeiam esse fenômeno e desvelar estratégias de ações para amenizá-lo.

Este artigo é um recorte do projeto matricial, visando compreender aspectos culturais que permeiam os cuidados de saúde na população quilombola Mutuca-MT, especificamente o autocuidado das mulheres negras quilombolas como estratégia de manutenção e resgate da saúde frente às dificuldades quanto ao acesso aos serviços médicos.

Consideramos que se debruçar sobre essa problemática se reveste de relevância social e profissional, por ser um potencial canal de conhecimento aos profissionais enfermeiros e demais profissionais da área da saúde quanto à resiliência das mulheres quilombolas, seus saberes e fazeres no cuidado da própria saúde, dos membros da comunidade e do meio ambiente como um todo. Para assim, torna-se clara a importância dos profissionais em negociar saberes acadêmicos com os populares na arte de cuidar da saúde.

Sobre essa questão, é fundamental evidenciar quanto à importância da negociação cultural na arte do cuidar/cuidado de enfermagem, para que o processo de cuidar não afronte as crenças, valores e saberes de quem está sendo cuidado e, assim, o processo terapêutico seja efetivo em sua essência e sentido ontológico ${ }^{(5,6)}$.

Objetivou-se desvelar a compreensão das mulheres quilombolas quanto ao autocuidado em saúde com vistas a intercambiar esses saberes e fazeres populares com os acadêmicos de enfermagem.

\section{METODOLOGIA}

Este é um estudo descritivo, com abordagem qualitativa, desenvolvido na Comunidade Quilombola Mutuca, a qual 
se localiza no distrito de Mata Cavalo - Mato Grosso, pertencente ao município de Nossa Senhora do Livramento. A pesquisa se desenvolveu entre agosto de 2018 e março de 2019.

Os sujeitos da pesquisa foram mulheres negras quilombolas pertencentes à comunidade supracitada, os dados de pesquisa foram coletados através do método roda de conversa, sendo esse um momento permeado de dinâmicas estimuladoras para participação e subsidiado por um tema gerador.

Durante as rodas de conversa, as falas foram apreendidas através de gravações de áudio, observação simples, registro de imagens com fotos e filmagens. Todo o processo se deu após as mulheres concordarem e assinarem o Termo de Consentimento Livre e Esclarecido (TCLE), conforme se preconiza a Resolução n. ${ }^{\circ}$ 466/2012 do Conselho nacional da Saúde / Ministério da Saúde (CNS/MS). Sendo assim, este estudo é recorte do projeto matriz aprovado pelo Comitê de Ética em Pesquisa / Saúde da UFMT, sob o parecer n. ${ }^{\circ} 2.714 .638 / 2018$.

Para análise e compreensão dos fenômenos apreendidos durantes as rodas de conversa, as falas foram categorizadas segundo a técnica de categorização preconizada por Bardin ${ }^{(7)}$ e, em seguida, compreendidas com subsídio da fenomenologia merleaupontyana $^{(8)}$, e literaturas norteadoras do estudo em epígrafe.

\section{RESULTADOS E DISCUSSÃO}

\section{Compreensões dos fenômenos apre- endidos nas rodas de conversa}

A enfermagem tem como uma das suas principais ações cuidativas educar os indivíduos, famílias e comunidades para o desenvolvimento do autocuidado. Nesse viés, como nos ensina Paulo Freire ${ }^{(9)}$, nenhuma pessoa é uma caixa vazia, sem conteúdo ou conhecimento, mas todos trazem de suas vivências e aprendizagens no convívio social uma bagagem ampla de conhecimentos que devem ser considerados no processo educativo. Assim, buscamos, nesta pesquisa, através da apreensão dos fenômenos relacionados ao autocuida- do expressos nas falas das mulheres negras quilombolas, desvelar como essas o compreendem e desenvolvem no seio da comunidade Mutuca - MT.

Para compreender os fenômenos implícitos nas falas, estas foram sistematizadas e agrupadas por sentidos homólogos (semelhantes), sendo utilizado, nesse processo, o princípio qualitativo de exaustão (quando as falas começam a se repetir por meio de semelhanças de sentido). Após realizado este processo, as falas foram agrupadas segundo a técnica de categorização de Bar$\operatorname{din}^{(7)}$, resultando nas categorias abaixo:

\section{Autocuidado com o meio ambiente "Não fazendo queimadas para não prejudicar a natureza, a minha saúde e do próximo".}

"Junto todas as folhas para depois fazer adubo, sem precisar queimar".

\section{"Não utilizando venenos nas plan-} tações de arroz e outras".

Essa categoria demonstra as atitudes das mulheres quilombolas do Mutuca em relação à dimensão do autocuidado com o meio ambiente, cujas falas levam-nos a inferir a consciência individual e coletiva quanto à preservação do meio-ambiente $\mathrm{e}$ técnicas inerentes à agroecologia, as quais contribuem direta e indiretamente para o resgate e manutenção da saúde individual e comunitária.

Os autores ${ }^{(10)}$ corroboram nossa compreensão ao afirmarem que, evitando queimadas, as quais provocam enormes consequências negativas para o ambiente e à saúde do indivíduo, obtém-se como resultado a prevenção do surgimento de doenças no trato respiratório, tais como: asma, bronquite, irritação dos olhos e garganta, conjuntivite, tosse, falta de ar, vermelhidão e alergia na pele, além de desordens cardiovasculares.

Alguns autores ${ }^{(10,11)}$ versam sobre a importância da agroecologia para a preservação do meio ambiente e do indivíduo. Nesse sentido, a não utilização de agrotóxicos é muito importante, tendo em vista que estes são um dos maiores fatores de ris- cos para a saúde humana, pois provocam danos à saúde das populações, dos trabalhadores particulares e ao meio ambiente.

Desse modo, percebemos, nesta categoria, que as mulheres quilombolas detêm compreensão e práticas importantes no que se refere ao autocuidado com o meio ambiente em sua comunidade.

\section{Autocuidado com os alimentos}

"Fazemos uma boa lavagem dos alimentos antes de consumi-los e, se possivel, às vezes deixamos ele imerso em algum produto químico por alguns minutos antes de prepará-lo".

\section{"Lavo bem as mãos antes de prepa- rar a comida".}

\section{"Evito colocar muito sal nos alimentos".}

Nessa dimensão do autocuidado, podemos visualizar o nível de conhecimento dos quilombolas, embora seja empírico, demonstra habilidades de autocuidado com os alimentos.

As falas inter-relacionam-se destacando sensibilidade e saberes cuidativos que as mulheres quilombolas do Mutuca têm com os alimentos, os quais transitam desde o plantio, higienização no preparo, armazenamento, até a ingestão, mesmo a maioria delas não tendo elevados graus de instrução formal.

É interessante ressaltar que, devido ao fato de algumas pessoas da comunidade terem sido diagnosticadas com hipertensão, há uma parcela da comunidade que já prepara os alimentos evitando adicionar o sal, substituindo-o por outro tempero, como o suco de limão.

As ações de autocuidado com os alimentos desenvolvidos pelas mulheres do quilombo são legitimadas, enfatizando que a lavagem dos alimentos com água potável permite a remoção de componentes do solo e alguns patógenos ${ }^{(12)}$.

Sobre essa questão, ressalta-se que o consumo de sal na dieta é um dos principais fatores de risco para a hipertensão arterial sistêmica, sendo reconhecido como uma das maiores causas de morbimortalidade e doenças cardiovasculares ${ }^{(13)}$. 
Nesta categoria, podemos desvelar que os quilombolas participantes do estudo em questão demonstraram desenvolver autocuidado com os alimentos, o qual transcende apenas o fato de prepará-los para o consumo e reveste-se de diligências que transitam desde o plantio até a ingestão livre de agrotóxicos ou sujidades transmissoras de patógenos.

\section{Autocuidado com a saúde individual \\ "Me cuido consumindo mais ali- mentos produzidos na própria co- munidade".}

"Tomando remédios caseiros da própria comunidade e os meus avós faziam e me ensinou".

"Ouvindo nossas mães e avós quanto aos cuidados com a saúde".

"Utilizando raizes, garrafadas e banhos de assento aprendidos com minha avó e mãe, para conter hemorragias e outras coisas próprias de mulheres".

Quanto ao autocuidado individual desenvolvido pelas mulheres quilombolas, identifica-se um forte componente cultural, cujos saberes e fazeres transmitidos pelos ancestrais (avós, mães e demais membros com mais idade da família e/ou comunidade) são considerados e executados por elas em seu autocuidado.

Nesse sentido, mulheres da comunidade declararam utilizar banhos de assento preparados com plantas medicinais, raízes e outros cuidados culturais no pós-parto. Tais recursos também são utilizados para tratar algumas patologias ginecológicas, garantindo êxito no resgate da saúde feminina.

Sobre tal ação cultural, enfatiza-se que o autocuidado não deve ser relacionado apenas ao presente, pois ele está intimamente ligado ao passado. Sendo assim, traz influências culturais aprendidas no seio familiar e na comunidade, as quais influenciam as atitudes futuras dos membros das comunidades quilombolas ${ }^{(14)}$.

Portanto, o autocuidado é uma ação permeada de crenças, valores e bagagens culturais que transcendem o conhecimento puramente técnico-acadêmico. Assim, salientamos que tais elementos devem ser considerados pelos profissionais da saúde na arte do cuidar-cuidado em comunidades tradicionais.

Este desvelamento corrobora a inquestionável necessidade de melhor preparo dos profissionais da saúde para atenderem essas mulheres com uma comunicação e escuta ativas, para que saibam fazer negociações culturais com elas, buscando identificar, na coleta da história de vida e saúde dessas usuárias, quais as práticas aprendidas com seus ancestrais que acreditam e desenvolvem no cuidado com a sua própria saúde, para que, assim, os profissionais possam identificar possibilidades de diálogos terapêuticos.

Autocuidado a partir da ajuda de profissionais de saúde

"Procuro seguir a orientação da enfermeira do posto quanto a manter a vacina das crianças em dia".

"Busco sempre conversar com a enfermeira quando vou ao posto, realizando a medição da pressão e fazendo os exames que o médico pede".

"Uma coisa que aprendi e procuro fazer é não deixando a caixa d'agua aberta para evitar a criação do mosquito da dengue".

"Nem sempre sigo o que me orientam, porque às vezes eles não respeitam nossa cultura quanto ao que fazemos para cuidar da saúde".

Nesta categoria, podemos observar dois fenômenos relevantes: algumas mulheres referiram desenvolver autocuidado considerando as orientações recebidas pelos profissionais de saúde da atenção primária (ESF/UBS). Entretanto, a maioria das participantes apontou utilizar com mais veemência ações de autocuidado a partir dos ensinamentos e aprendizagens adquiridas com os seus ancestrais e/ou membros da comunidade, fenômeno legitimado pelas várias citações quanto ao uso de chás caseiros, raízes e outras práticas culturais. Fato também observado durante as rodas de conversa e visitas à comunidade.

Geralmente, as mulheres nessas comunidades utilizam práticas cuidativas à base de plantas medicinais, rituais religiosos (benzeções), entre outras aprendidas com seus antepassados. Dessa forma, nota-se a importância de os profissionais conhecerem e respeitarem esses aspectos culturais ao abordá-las nas consultas.

As comunidades tradicionais, em função da forte influência do meio natural, apresentam modos de vida e cultura diferenciados. Seus hábitos estão diretamente submetidos aos ciclos naturais, sendo que a forma como apreendem a realidade e a natureza é baseada não só em experiências e racionalidades, mas em valores, símbolos, crenças e mitos, devendo os profissionais da saúde considerar tais fatores ao lidarem com essas comunidades ${ }^{(15)}$.

Nas comunidades tradicionais, a flora medicinal constitui um arsenal terapêutico, pois há várias décadas as plantas vêm sendo utilizadas como fontes medicamentosas empregadas em preparações tradicionais de cura na comunidade, através de chás, tinturas, garrafadas, sucos, xaropes, unguentos, entre outros ${ }^{(16)}$. Em contraste a isso, um quilombola afirmou que se sentiu desrespeitada por alguns profissionais quanto à abordagem grosseira que recebeu ao narrar as práticas de cuidado com a saúde que desenvolvia a partir da sua cultura. Frente a tal atitude, a mesma não se sentiu disposta a retornar ao serviço de saúde.

Nesse sentido, ressaltamos ser urgente e necessário que as universidades e demais instituições formadoras busquem, no processo de formação acadêmica, preparar os futuros profissionais. Para tanto, as questões culturais (crenças, valores, costumes) inerentes às comunidades tradicionais (quilombolas, nesse caso, mas podem ser indígenas, ribeirinhas, pessoas de terreiro, etc.) a que pertencem os usuários dos serviços de saúde devem ser consideradas, visando um cuidado efetivo, humanizado e, sobretudo, com respeito aos povos em suas tradiçôes, saberes e fazeres. 


\section{CONSIDERAÇÕES FINAIS}

O cuidado em saúde é uma ação permeada de significados e significâncias (sentidos), portanto, composto por crenças, valores, costumes, afetos e visão de mundo de cada um, pois cada pessoa é singular no seu modo de ver, viver e sentir a vida e o mundo em movimento. Assim, a forma como cada indivíduo percebe a saúde e cuida-se também é única e singular, sendo tal construção resultado das relações intrafamiliares e sociais ${ }^{(17)}$.

Essas tradições culturais se fazem presentes em todas as dimensões do autocuidado humano, fato legitimado nas falas e vivências socializadas pelas mulheres negras quilombolas, as quais desvelaram a profundidade dos seus saberes e fazeres entrelaçados com a natureza e toda a riqueza que esta proporciona ao ser humano. As mulheres quilombolas, em sua simplicidade de ser e viver, apresentam a riqueza do outro, do coletivo, da cultura, do mundo em movimento, possibilitando-nos novas aprendizagens e reflexões quanto à arte de saber cuidar dos povos das comunidades tradicionais.

Assim, consideramos, a partir deste estudo e dos fenômenos desvelados, que os cursos da área da saúde, de modo específico o de Enfermagem, busquem desenvolver projetos que aproximem os futuros profissionais dos saberes e fazeres culturais das comunidades tradicionais, possibilitando aos potenciais egressos enfermeiros uma formação que ultrapasse os muros da universidade e que se dê em outros espaços, onde a abstração teórica não acontece caso não esteja viva e seja vivida no cotidiano de cada sujeito envolvido: docente, discente e comunidade.

Nessa perspectiva, enfatizamos que a formação na área da saúde precisa criar mecanismos para diminuir a distância simbólica e cultural entre saber técnico e cultural, para que assim ocorra o que Leininger denominou "Negociação cultural do cuidado" e, finalmente, a saúde seja uma construção social mediada pela ação dos enfermeiros.

\section{REFERÊNCIAS}

1. Ministério da Saúde (BR). Política Nacional de Atenção Integral a Saúde das Mulheres. Princípios e Diretrizes [Internet]. Brasilia (DF): MS, 2004 [acesso em 18 jul 2018]. Disponivel em: www. http:// bvsms.saude.gov.br/bvs/publicacoes/politica_nac_atencao_mulher.pdf.

2. Prates LA, Scarton J, Barreto CN, Cremonese L, Possati AB, Resselt LB. O olhar feminino sobre o cuidado à saúde da mulher quilombola: Nota prévia. Rev enferm UFPE on line [Internet]. 2014 [acesso em 2018, ago 18]; 2194-8. Disponivel em https://periodicos.ufpe.br/revistas/revistaenfermagem/article/viewFile/9903/10169.

3. Ministério da Saúde (BR). Portaria n. ${ }^{\circ}$ 992, de 13 de maio de 2009. Institui a política nacional de saúde integral da população negra, uma política do sus [Internet]. Brasilia (DF): MS, 2009 [acesso em 10 ago 2018]. Disponivel em: http://bvsms.saude.gov.br/bvs/publicacoes/politica_nacional_saude_integral_populacao.pdf.

4. PrestesCRS, Paiva VSF. Abordagem PsicossocialeSaúdedemulheres negras: Vulnerabilidade, direitos e resiliência. Rev Saúde Soc [Internet] 2016 [acesso em 10 ago 2018]; 25(3). Disponivel em: http://www.scielo.br/pdf/sausoc/v25n3/1984-0470-sausoc-25-03-00673.pdf.

5. George J. B. Teorias de Enfermagem: os fundamentos a prática de enfermagem. Porto Alegre: Artmed; 2000.

6. Leininger M. Transcultural nursing concepts, theories, research\& pratices. Madrid: McGraw-Hill; 1995.

7. Bardin L. Análise de conteúdo. São Paulo: Edições 70; 2011.

8. Merleauponty M. Fenomenologia da percepção. Tradução de Carlos Alberto Ribeiro Moura. 3. ed. São Paulo: Martins Fontes; 2006.

9. Freire P. Pedagogia da autonomia. São Paulo: Paz e Terra; 1996.

10. Ribeiro $H$, Assunção JV. Efeitos das queimadas na saúde humana. Estudos avançados [Internet]. 2002 [acesso em 10 ago 2018]; 16(44):125-148. Disponivel em: http:/www.scielo.br/pdf/ea/v16n44/ v16n44a08.pdf.
11. Pinheiro TM, Faria PH, Silva NE, Silvan JM. Agrotóxico e trabalho: uma combinação perigosa para a saúde do trabalhador rural. Ciência \& Saúde Coletiva [Internet]. 2005 [acesso 2019 mai 08]; 891-903. Disponivel em: http:/www.scielo.br/pdf/csc/v10n4/a13v10n4.pdf.

12. Joshi $K$, mahendran $R$, Alagusundaram $K$, Norton T, Tiwari BK. Novel disinfectants for fresh produce. Trends in food science \& technology [Internet]. 2013 [acesso em 01 abr 2019]; 34(1):54-61. Disponível em: https://reader.elsevier.com/reader/sd/pii/S0924224413001830?token=90366BD76DF556FB8ACDCFC8045AB6A242A012216835AC9308C5D2FDBD80A20C3A7480595A2BA0A7A2A2AE54A3E79166.

13. SAarno F, Claro RM, Levy RB, Bandoni DH, Monteiro CA. Estimativa de consumo de sódio pela população brasileira 2008-2009. Rev Saúde Pública [Internet]. 2013 [acesso 2018 dez 15]; 572-78. Disponivel em: http://www.scielo.br/pdf/rsp/v47n3/0034-8910rsp-47-03-0571.pdf.

14. Andrade JS, Barroso BYC, Santos FAZ, Lima GS, Lopes TCR, Oliveira FBM. Capacidade de autocuidado em saúde na população negra quilombola. ReonFacema [Internet]. 2016 [acesso em 2019 mar 18]; 2(4):291-296. Disponivel em: http://www.facema.edu.br/ojs/index. php/ReOnFacema/article/viewFile/160/66.

15. Monteles R, Pinheiro CUB. Plantas medicinais de um quilombo maranhense: uma perspectiva etnobotânica. Biologia e ciências da terra [Internet]. 2007 [acesso em 01 abr 2019]; 7(2): 17-37. Disponivel em: http://joaootavio.com.br/bioterra/workspace/uploads/artigos/etnobotanica-518178b5ca552.pdf.

16. Franco EAP, Barros RFM. Uso e diversidade de plantas medicinais no Quilombo Olho D'água dos Pires, Esperantina, Piauí. Rev. Bras. PI. Med. [Internet]. 2006 [acesso 2018 Dez 15];8(3):78-88. Disponivel em: http:/www.sbpmed.org.br/download/issn_06_2/artigo12_v8_ n3.pdf.

17. Martinho NJ. Sentidos e significados de educação em saúde a partir da homeopatia popular: Uma compreensão fenomenológica. [Tese]. Cuiabá, Universidade Federal de Mato Grosso - UFMT; 2014. 